\title{
Contest vs. scramble competition among males pursuing fixed or plastic alternative reproductive tactics
}

Corinna von Kuerthy ${ }^{*}$ and Michael Taborsky

Behavioural Ecology, Institute of Ecology and Evolution, University of Bern, Wohlenstr. 50a, 3032 Hinterkappelen, Switzerland.

Corresponding author: corinna.vonkuerthy@iee.unibe.ch

\begin{abstract}
Reproductive and agonistic behaviours typically diverge between individuals pursuing alternative reproductive tactics (ARTs). When tactics are fixed for life, evolutionary theory predicts that the relative frequencies of alternative male genotypes are stabilized in a population by negative frequency dependence. This implies that competition is greatest between males pursuing the same tactic. The cichlid fish Lamprologus callipterus exhibits three male ARTs involving fixed and flexible tactics, and an extreme intrasexual size dimorphism determined by Mendelian inheritance. Large nest males defend territories and construct nests of empty snail shells in which females breed. In contrast, dwarf males pursuing a genetically fixed parasitic tactic enter shells surreptitiously during spawning in order to steal fertilizations. Sneaker males using another parasitic tactic, which is plastic and conditional, steal fertilizations opportunistically during spawning by quick intrusions into the nest. The variation in tactic origin and reproductive behaviour, and the substantial asymmetry in body size render L. callipterus an ideal model system to study theoretical predictions
\end{abstract}


regarding the types and intensity of contest behaviours among conspecific competitors pursuing ARTs. In an experiment exposing males to competitors using either the same or a different tactic, within-tactic competition was much more intense than between-tactic competition in bourgeois males, as predicted by evolutionary theory. In addition, the level of aggression displayed by bourgeois males against male intruders is apparently triggered by perceived differences in body size. In contrast to bourgeois males, parasitic males hardly showed aggressive behaviour against other males, indicating that their contests follow the pattern of scramble competition. The conditions characterising parasitic reproduction apparently select for rapid responsiveness when opportunities arise to fertilize eggs, whereas attacking other males in this situation seems inappropriate. Our data show that males pursuing ARTs diverge in the way they react to reproductive competition, mainly dependent on their overall resource defence strategy.

keywords: bourgeois and parasitic males, cichlid fish, Lamprologus callipterus, social challenge, tactic specific rivalry,

\section{Introduction}

Male:male competition is common in the context of reproduction, and it is particularly intriguing if males pursue alternative reproductive tactics (ARTs; Gross 1996; Shuster \& Wade 2003; Oliveira, Taborsky \& Brockmann 2008; Taborsky \& Brockmann 2010). ARTs are characterized by bimodal or multimodal distributions of behavioural, physiological and sometimes morphological traits among same-sex conspecifics, typically in males, which result 
from disruptive sexual selection (Taborsky et al. 2008; Taborsky \& Brockmann 2010). A crucial distinction between ARTs is their fundamentally different reproductive effort. At the behavioural level, large "bourgeois" males generally defend and monopolize reproductive resources, which creates opportunities for non-courting male competitors to exploit their effort (Taborsky 1994, 1997; Neff et al. 2003). Males of the bourgeois pathway compete by investing heavily into growth (Wirtz Ocaña et al. 2013), conspicuous body ornaments (Neat et al. 2003; Candolin \& Wong 2008), territorial and courtship behaviour (Gross 1982; Gross 1996; Taborsky \& Brockmann 2010), extended phenotypes (Schaedelin \& Taborsky 2006; Schaedelin \& Taborsky 2009), weaponry (Tschernavin 1938) and acoustic or chemical signals (Laumen et al. 1974). In contrast, parasitic males typically benefit from an inconspicuous appearance when approaching a nest surreptitiously in order to steal fertilizations, thus exploiting the effort of bourgeois males (Warner 1984; Taborsky 1994). ARTs may be fixed for life (Zimmerer \& Kallmann, 1989; marine isopod: Shuster \& Wade 1991; swordtail: Ryan et al. 1992; corkwing wrasse: Uglem et al. 2002) in which case individual males permanently differentiate into one of the tactics, or they may be plastic (atlantic salmon: Aubin-Horth et al. 2004; dung beetle: Knell \& Simmons, 2010; columbian ground squirrel: Raveh et al. 2010; african striped mouse: Schradin \& Lindholm, 2011) and males may switch tactics reversibly or irreversibly during their lifetime (Taborsky et al. 2008). Althought there are numerous descriptive studies of plastic and fixed ARTs, information is scarce on how individuals of different tactics react and adjust to within vs. between-tactic competition during reproduction. However, when indivuals pursue different ARTs, reproductive competition may occur at either of two levels: for access to mates, or directly for fertilization of eggs or females. As a consequence, an individual may need to adjust the behaviour depending on its tactic and depending on the form of competition it is facing (e.g. within vs. between-tactic competition). 
Evolutionary theory predicts that fixed ARTs are maintained by frequency-dependent selection (Maynard Smith 1974; Gross 1991). The logic is that if bourgeois male frequencies increase in a population, the average fitness of individuals performing a parasitic tactic would increase relative to the fitness of males pursuing the bourgeois tactic (Taborsky et al. 2008). This is because competition between males pursuing the same type of behaviour is predicted to be more intense than competition between males using different tactics when contesting for resources and mates (Maynard Smith 1974; Austad 1984; Gross 1991; Shuster \& Wade 2003; Taborsky \& Brockmann 2010).

Here we aim to compare tactic specific rivalry in fixed and plastic ARTs. As a model we use the polygynous and biparental, snail-shell brooding cichlid Lamprologus callipterus from Lake Tanganyika, East Africa. This species is particularly interesting because males show both fixed alternative life-history pathways and plastic tactic choice in one of the two alternative pathways (Wirtz Ocaña et al. 2014). In addition, alternative male tactics in this species exhibit an exceptional size dimorphism (Taborsky 2001; Sato et al. 2004). Large bourgeois nest males of L. callipterus collect empty snail shells (Mitchell et al. 2014) and defend them against other males and predators (resource defence polygyny; Emlen \& Oring 1977), thereby providing protection to females breeding inside these shells (Emlen \& Oring 1977; Sato 1994; Sato et al. 2004). The time a bourgeois male monopolizes and defends a nest can differ considerably between individual males (Schütz et al. 2010). During the nest holding period, bourgeois males are frequently challenged by other potential nest males trying to steal shells or to take over a nest (Maan \& Taborsky 2008), and by the interference of males pursuing one of two alternative mating tactics attempting to parasitize their reproductive 
effort (Taborsky 1998, 2001; Sato et al. 2004). Firstly, sneaker males of the bourgeois male pathway, typically younger and competitively inferior males, try to occasionally steal fertilizations from nest owners by opportunistically darting into a nest male's territory during spawning. When passing a certain threshold size (Schütz \& Taborsky 2005) and after accumulating sufficient energy stores (von Kuerthy et al. 2015), these males may switch from sneaker to nest male status attempting to hold a territory by themselves. The second parasitic tactic is employed by the much smaller and genetically divergent dwarf male tactic, which halts growth long before reaching female size and weighs only $2.4 \%$ of nest males on average (Taborsky 2001; Sato et al. 2004; Schütz \& Taborsky 2005). Dwarf males exist at low relative frequencies in natural populations (Goffinet 2007; Wirtz Ocaña et al. 2014) and pursue a different life-history pathway with a highly specialized mating behaviour. Dwarf males try to steal fertilizations from territory holders by wriggling past a spawning female into the tip of the snail shell (Taborsky 1998, 2008; Sato et al. 2004). From this position, they typically fertilize the majority of the eggs of a female (Wirtz Ocaña et al. 2014). The asymmetry in size and behaviour renders L. callipterus an ideal study system to study contests among conspecific competitors pursuing different ARTs.

Here we study tactic specific rivalry in L. callipterus during courtship. We tested bourgeois males, as well as plastic parasitic sneakers and fixed parasitic dwarf males in different standardized competitive test situations in order to quantify the responses of each tactic to (i) within vs. (ii) between-tactic competition. We predicted that parasitic sneaker and dwarf males should rather stay inconspicuous, avoiding overt contests with bourgeois males, and as a consequence avoiding the costs of being attacked, chased or even injured. We expected between-tactic competition to generate a different response in nest males, because parasitic sneaker males usually pose a different and typically smaller threat (loss of some paternity) for 
the bourgeois males than competitors of the same tactic (potential nest take overs; Maan \& Taborsky 2008). Dwarf males may pose a higher threat to the nest male (major loss of paternity for a particular brood; Wirtz Ocaña et al. 2014) than parasitic sneaker males, but much less threat than a bourgeois male intruder that may take over the nest and terminate the reproductive success of the nest owner altogether. We test whether nest males respond appropriately to the different threats arising when parasitic sneakers or dwarf males intrude into their nest. We differentiated whether their response is based for instance on the body size or behaviour of an intruder, or whether it is based on the actual threat to be expected in terms of future stolen paternity.

Since each male tactic is predicted to incur the highest level of competition from rivals pursuing the same tactic, which results in negative frequency dependence, we also expected high levels of competition between males pursuing the same parasitic tactics. However, in parasitic males scramble competition (Toquenaga 1990) selecting for a rapid response when opportunities for reproduction arise might be a more appropriate way to compete, because such situations are hard to predict and responses should be swift. Ultimately, the intensity of contests between different tactics may strongly influence the amount of time nest males can invest in reproductive behaviours, and the amount of time needed to succeed in a contest may differ among different within vs. between-tactic contest situations.

Understanding how individuals pursuing different ARTs adjust to heterogeneous social environments and different forms of competition is important to our understanding of selective forces acting on males using ARTs.

\section{Material and Methods}




\section{Experimental design}

Focal nest males of L. callipterus were placed in $\sim 500$ litre compartments $(\sim 130 \mathrm{~cm} \times 63 \mathrm{~cm}$ $\mathrm{x} 63 \mathrm{~cm}$ ) of 1000 litre tanks. We used wild caught individuals from Lake Tanganyika and F1 descendants. Nest males were introduced into the compartment one week prior to the start of the experiment, and remained in the tank during the entire experimental period. Six empty snail shells of Neothauma tanganyicense, the standard breeding substrate of L. callipterus, were introduced into the tank on the day before the experiment started in order to induce territorial behaviour in focal nest males. Additionally, several hiding opportunities (empty cut-up plastic bottles and clay flowerpot halves) were placed in each tank. The water temperature was kept constant at $27^{\circ} \mathrm{C} \pm 2{ }^{\circ} \mathrm{C}$ and the day:night cycle was $13: 11 \mathrm{~h}$. Salinity and hardness of the water matched the values of Lake Tanganyika closely (Taborsky 1984) and all fish received food ad libitum twice a day (TetraMin: dry food/ fresh food: Artemia, Daphnia or Mosquito larvae). On the experimental day, two ovulating females were introduced to the focal nest male's tank at ca. 8.45 a.m. ( $\pm 30 \mathrm{~min})$.

Induction of ovulation in females

Ovulation in L. callipterus females was induced by interperitoneal injection of LHRH (desGly10[D-Ala6]-Luteinizing Hormone-Releasing-Hormone-Ethylamide, Sigma-Aldrich L4513) at $70 \mu \mathrm{g}$ LHRH/10g female body weight, following an established protocol (Hirschenhauser et al. 2004) using a stock solution of LHRH mixed with freshwater teleost Ringer solution. This dosage results in an ovulation peak after approximately 48 hours (Hirschenhauser et al. 2002). Ovulation in females was checked by inspecting the belly and genital papilla swelling (Trewavas 1983). After the introduction of the female to the experimental tank (Fig. 1), courtship usually commenced without delay. The induction of 
ovulation in females allowed us to test a specific nest male's behavioural response to the presence of an ovulating female during a direct interaction with different conspecific male tactics in a standardized way.

The experiment comprised two major experimental phases. 1. Pre- exposure-phase: Initially, the nest males were kept in the experimental tank solely with two females for one hour. This phase without presence of male competitors served to initiate territorial and courtship behaviours. 2. Non-competitive or competitive exposure phase: At the beginning of the second hour, a focal nest male was challenged with one of five possible test situations (Fig. 1, a-e). In the non-competitive test situation (a), the focal nest male was continuously kept together with only two females for both the pre-exposure phase and the exposure phase. In the competitive male-exposure phase (b-e), the focal nest male was confronted with either (b) a size-matched potential nest male $(\mathrm{Nm})$, (c) two sneaker males $(\mathrm{Sn})$, (d) two dwarf males $(\mathrm{Dw})$, or (e) one sneaker and one dwarf male (Mix: SnDw) for another hour (second hour of the experiment). The mixed test situations (Fig. 1, e), in which all three male tactics were present at the same time, was used for a direct comparison of the response levels of the different male tactics in a between-tactic test situation. In total, focal nest males remained in the tank until 5 hours after the start of the experiment, when they were observed for the last time in order to test for potential time effects on their adjustment to a certain test situation. Our experimental design allowed us to investigate behavioural interactions between individuals of the same tactic, and interactions between territorial nest males with males of the two parasitic tactics. Also, the challenge nest male intruders pose for a nest owner is inherently different from the challenge posed by parasitic males, because territory ownership is at stake in the first case, and competition for fertilization of some eggs in the second. Furthermore and perhaps most importantly, competitors for territory ownership, i.e. intruding males of the nest male type, usually act singly in nature, whereas reproductive parasites often 
occur in groups. Therefore, our experimental design represents the best compromise possible for these experimental challenges between natural conditions and proper experimental control.

\section{Fig.1.MSvonKuerthy}

Focal nest males (total length of the fish $(\mathrm{TL}): 10.0-12.6 \mathrm{~cm}$ ) were sequentially tested in randomized order in each of the 5 test situations (a-e), with one-week isolation intervals between the subsequent test situations. All fish were disturbed in a similar manner during the start of the experiment and at the start of the exposure phase, namely by opening the lid of the tank and slightly splashing the water at the surface (control) or by adding the intruder fish to the tank, respectively. Intruders from the nest male type (TL:10.0-12.1 cm) were chosen to be size matched whenever possible $( \pm 5 \mathrm{~mm})$. Sneaker males were significantly smaller than nest males (TL: 6.6- $9.9 \mathrm{~cm}$ ) but were assumed to be sexually mature, because they previously had been observed to intensely interact with females in their original holding tanks. Within the (c) sneaker and the (d) dwarf male (TL: $3.3-4.3 \mathrm{~cm}$ ) test situations, the two male intruders from the same tactic were size matched. In the (e) mixed tactic test situation the focal nest males always received new parasitic intruder males that they had not previously met in other test situations (c or d). During the entire experiment, focal individuals were allowed to freely interact with each other. We used fixed digital cameras placed in front of the aquaria to record all interactions of focal individuals

Behavioural observations 
In all five test situations (Fig. 1 a-e), we quantified total aggression in seconds displayed by the nest owner towards intruder males and also the number of aggressive categories (overt aggression: chasing and biting, and restrained aggression: fast approaches, head down postures, fin spreading, opercula spreading; see Schütz et al. 2005). Additionally, we quantified total courtship behaviour in seconds (including zigzag swimming, bumping and shell mouthing; see Schütz et al. 2012), aggressive behaviour in seconds (as described above) exhibited towards females only, nest maintenance behaviours in seconds (shell manipulation, sand transport) and passive behaviour in seconds (lying on ground, or floating above ground). Behaviours were quantified with the aid of the software "The Observer 5.0" (Noldus, Wageningen, The Netherlands). Each focal nest male was observed twice for 5 minutes (Fig. 1, observations $=$ X) 20 and 40 minutes after the start of the exposure phase, when alone with the two females (Fig.1 a), or when in a competitive test situation with intruder males, respectively (Fig. 1 b-e). We also recorded within- and between-tactic competition in parasitic males, as well as the time nest males displayed aggressive behaviours towards females, during the different test situations. After nest males had spent 1 hour solely with the females (Fig. 1) and then one hour in the exposure-phase with other males (or alone respectively in the control; Fig. 1 a-e), individuals were sampled for hormones for another study. To allow repetitive, non-invasive measurements after different test situations and to avoid invasive blood sampling, steroids were measured from fish-holding water, which was obtained by adding focal individuals to a glass beaker with clean sampling water (Hirschenhauser et al. 2002, 2004; Oliveira et al. 2002, 2003; Scott \& Ellis 2007; Scott et al. 2008). Afterwards, they were returned to the experimental tank and continued interacting with each other. We allowed individuals to interact with each other for the rest of the experimental day, and another recording of total nest male aggression (seconds) was taken five hours after the start of the 
experiment. This observation was made in order to test whether nest males had resolved the different contests in all five different competitive test situations at this point in time.

\section{Ethical note}

This experiment was approved by the Federal veterinary office of the canton Bern, Switzerland. For the induction of ovulation with LHRH, females $(\mathrm{N}=50)$ were slightly anaesthetized using MS222. Following the injection with LHRH, 4 females at a time were kept in a 200 litre stimulation tank for a period of 48 hours, with a nest male for reproductive stimulation, snail shells unsuitable for breeding, and several hiding places. This allowed us to survey the females' condition and behaviour in the period between the injection and the introduction to the experimental tank. No adverse effects of the treatment were observed at any time during the entire experiment. 13-15 focal nest males were challenged by the 5 different test situations. During the challenge we surveyed the tanks with help of digital cameras to check for the condition of all individuals and in order to prevent escalations of potential combats. None of the experimental individuals were injured during these trials. We intended to end a test phase if there were any signs of physical damage caused by aggressive interactions. However, in only one case we had to stop the experiment due to intense physical aggression between two nest males. At the end of the test phase, we removed all snail shells from each experimental tank, which led to an immediate decrease in territorial and aggressive behaviour. Shortly thereafter, all individuals were returned to their respective home tanks where they continued to be part of our breeding program.

Statistical analysis 
The time of the two observations spent on nest male behaviours (in seconds), taken 20 and 40 min after the start of the exposure phase (Fig. 1 a-e), did not follow a trend that would suggest any time effects. We therefore calculated the mean of these two observations and used Linear Mixed Effects Models (LMEs) to analyse total aggressive behaviour (in seconds) and nest maintenance behaviours (in seconds), and compared each behaviour among the different test situations. In the same manner, we calculated the mean numbers of chasing and biting events (overt aggression), and the numbers of fast approaches, fin spreading, head down and opercula spreading displays (restrained aggression) during the exposure phase (second hour). Since we (i) calculated the mean of two observations (of two counts) and also due to the fact that (ii) after transforming our data, the residuals of our LMEs were normally distributed, we compared behavioural events among treatments using LMEs. For the comparison of aggressive behaviours among treatments, the control treatment was not included in the model, since we only compared the aggressive behaviours of nest males towards intruder males in the competitive test situations (see Fig. 1). Aggressive behaviours of nest males towards females and finally, total aggression (in seconds) of nest males among treatments at hour five were compared using LME.

Each LME included the behaviour as the response variable, the treatment as a fixed effect, and fish ID as a random effect. We used square root transformations of the response variables for most behaviours (means of total aggression, nest maintenance, fin spreading, chasing, fast approaches) to reduce heteroscedasticity. For the analysis of the means of head down, opercula spreading and biting displays among treatments we used boxcox transformations (Sakia 1992). Model assumptions of homoscedasticity and residual normality were tested using graphics and Shapiro-Wilk and Lilliefors (Kolmogorov-Smirnov) normality tests. Since none of the standard transformations lead to normally distributed residuals of one of our 
models, we used a permutation test (10000 permutations) to compare nest male courting behavior (in seconds) among treatments. Spearman's rank correlation analyses were used to test for a relationship between the amount of time nest males displayed aggressive behaviours and the amount they invested in either courtship or nest maintenance behaviours. All statistical analyses were performed using R 3.0.2. The R package "nlme" (Pinheiro, 2012) was used to perform all LMEs. Multiple post-hoc tests (Tukey) were performed using the "multcomp" package (Hothorn, Bretz \& Westfall 2008) and the "Mass" package was used for the permutation tests (Sakia 1992; Venables \& Ripley 2002). Adjusted $P$ values are reported. One subject was removed from the analysis since the fish was apparently sick and behaved abnormally on one of the measurement days. This fish died shortly afterwards. Two behavioural observations were lost due to technical problems. In total, our sample sizes were between $\mathrm{N}=13-15$ in the different test situations.

\section{Results}

\section{Aggressive behaviour}

There was a significant difference in the amount of time nest males exhibited aggressive behaviours among the different test situations during the exposure phase (LME: sqraggression vs. treatment: $F(3)=20.206, P<0.0001$; Table 1), with the highest level exhibited towards intruders of the nest male tactic (within-tactic competition; Fig. 2, Table 1) and the lowest level exhibited when exposed to intruders of the parasitic dwarf male tactic (betweentactic competition; Fig. 2, Table 1). Nest male aggression levels, in both the nest male and the dwarf male test situations, differed significantly from the sneaker and mixed tactic test situations, while no difference was found between the latter two (Fig. 2, Table 1; for single 
restrained and overt behaviours see Fig. A1a+A1b, and Table A1-A6 in the supplementary material).

\section{Fig.2.MsvonKuerthyRev2}

\section{Table 1}

When comparing nest male total aggression among treatments five hours after the start of the experiment, no differences among the different competitive test situations were found (Table A9 in the supplementary material).

We found neither between nor within-tactic aggression in parasitic males. The rare interactions we observed, e.g. between sneaker males, did not seem to be aggressive. Nest males almost never bit females during the exposure phase, nor performed any other threat behaviours, such as fin spreads, head down or opercular spreading displays towards females. They did, however, perform fast approaches and chasing of females, but the frequencies of these behaviours did not differ among treatments (Table. A7 + A8 in the supplementary material).

\section{Reproductive behaviour}

The amount of time nest males displayed courtship differed among treatments (Permutation test, $P<0.01$, Table 2). Courting levels were highest in the control treatment without intruder males, but did not differ among the competitive test situations (Fig.3a, Table 2). The time nest males displayed nest maintenance differed among treatments (LME: sqr-maintenance vs. 
treatment: $F(4)=2.60, P<0.05)$, with nest males spending significantly more time showing nest maintenance when in the control and the dwarf male treatment as compared to the nest male treatment (Fig. 3b, Table 3).

\section{Fig.3aMsvonKuerthyRev2}

Fig.3bMsvonKuerthyRev2

\section{Table 2}

\section{Table 3}

Relation between aggression and reproductive behaviour

We checked whether the time nest males displayed aggression was related to the time these males displayed reproductive behaviours (Fig. $4 a+4 b$ ). As the aggression shown against competitors is costly not only regarding energy expenditure and injury risk, but also the time expenditure (i.e., opportunity costs), we predicted a trade-off between the effort spent with contests and reproduction, including nest maintenance and courtship. There was a significant negative correlation between the mean time spent with aggressive behaviours and nest maintenance (Spearman's rank correlation analysis: $r s=-0.9, P<0.05$ ). However, no such relationship was found between mean courtship and aggression levels among the different competitive treatments (Table A10 in the supplementary material).

\section{Fig.4aMsvonKuerthyRev2}

\section{Fig.4bMsvonKuerthyRev2}




\section{Discussion}

Within tactic competition

As suggested by evolutionary theory (Maynard Smith 1974; Austad 1984; Shuster \& Wade 2003; Taborsky \& Brockmann 2010), we found tactic specific rivalry to be confirmed in nest males of L. callipterus, with "within-tactic" competition to be higher than "between-tactic" competition prior to spawning. The very high aggression levels of nest owners when challenged by sized-matched nest male intruders are expected (classical contest competition; Parker 1982) in a system where breeding resources are often scarce (Parker 1974). The payoff for winning a contest in general might be larger for an owner of a territory than for the intruder male, because the owner may have spawned with females already, or he may at least have started to spawn in his nest, hence he is protecting own offspring. These young and the female are typically expelled from their shells by a new owner (Maan \& Taborsky 2008).

The high aggression levels during nest male within-tactic competition were accompanied by high frequencies of biting, opercula spreading and fin spreading displays, and by fast approaches, as compared to all other test situations. Nest males clearly invest more into these presumably expensive behaviours when challenged for territory ownership than when encountering an intruder that might just fertilize some eggs (i.e., parasitic males). This higher defence effort of nest males against males of the same type may not only entail a higher injury risk, but also be one of the reasons for the decline of energy stores of nest males during their long nest holding period (von Kuerthy et al. 2015). One possibility to reduce costs from such escalated contests is the use of display behaviour revealing the size and strength of the nest owner. Opercula spreading most likely serves to demonstrate their body size. This behaviour was often displayed in contests with male intruders of the same male type, where size 
differences may be evaluated between opponents prior to escalation and potential injury. In this situation contestants can mutually assess their relative resource holding potential, which allows the weaker individual to terminate the contest before escalation, thereby reducing energy expenditure and the risk of injury (Arnott \& Elwood, 2009). However, in order to fully understand the meaning of these behaviours shown by L. callipterus during contests, their actual function should be further explored (Arnott \& Elwood 2010, 2012). Five hours after the start of the experiment there were no differences in aggression among treatments, indicating that contests had been resolved by then.

\section{Between tactic competition}

Nest male aggression levels towards dwarf males were significantly lower than in all other test situations. While chasing, fast approaches and biting was observed in some rare cases, restrained behaviours such as fin spreads, opercula spreads and head down displays were never displayed by nest males towards a dwarf male intruder. This makes sense because dwarf males can be expelled immediately when detected, without risk of injury to the attacking nest male due to the enormous size difference (1:40 on average; Sato et al. 2004).

The second highest aggression of nest males was found against sneaker males. While nest males chased and quickly approached sneaker males as much as they did when challenged by a potential nest male intruder, they performed significantly less overt biting and restrained fin spreads in the sneaker male treatment. The difference in the amount of time spent displaying aggressive behaviours between the sneaker male and nest male treatments suggests that sneaker males are perceived by the territory holder as a lower challenge than males potentially contesting territory ownership; only a minor loss of paternity is at stake when sneakers 
participate in spawning (Wirtz Ocaña et al. 2014). Selection should favour sneaker males avoiding direct contests (Taborsky 2008). The lack of aggressive displays by sneaker males and the obvious asymmetry with nest males in their resource holding potential may also be responsible for the rather low level of aggression nest males show against sneakers. Asymmetries in resource holding potential and body size typically explain the contest behaviour and outcome of male-male interactions (Hammerstein 1981), especially if they are as pronounced as in the case of males pursuing alternative reproductive tactics.

\section{Courting and nest maintenance}

As the aggression shown against competitors involves time expenditure, we predicted a tradeoff between the effort spent with contest and reproductive behaviours. The presence of intruder males, as compared to the control treatment without competitors, significantly decreased the amount of time nest males spent with courtship, but this reduction did not differ among competitive treatments. Nest maintenance behaviours (collecting shells, rearranging shells and presenting them to females) did not differ among the nest male, sneaker male and the mixed tactic test situations. However, nest males spent significantly more time with nest maintenance behaviours in the control situation and the dwarf male treatment, as compared to the nest male intruder situation. Besides attracting females to the nest, the increased investment into nest maintenance behaviour might also indicate nest male surveillance of shells in which dwarf males could hide (Sato et al. 2004). It appears that if nest males are challenged by large intruder males they are distracted and limited in their investment into nest maintenance behaviours.

Hence there seems to be a trade-off between the duration and intensity of a combat (aggression) and other reproductive duties such as nest maintenance and courtship behaviours. Aggression in the competitive intruder treatments therefore seem to cause opportunity costs. 
Within and between tactic competition - Parasitic males

We did not find aggressive interactions among dwarf males. Since the natural frequencies of dwarf males are low (Wirtz Ocaña et al. 2014), this kind of competition maybe rare in nature. Sneaker males also rarely interacted with each other in an aggressive manner. In both dwarf and sneaker males, a rapid scramble competition response when opportunities for parasitic reproduction arise seems to provide better fitness returns than contests, and may be more likely to stabilize their tactic frequencies (Toquenaga 1990). Although we did not witness clear scramble competition during our experiment, most likely due to the lack of spawnings during the exposure phase of our experiment, we assume that parasitic males in L. callipterus would show scramble competition during a spawning, which has been observed frequently in the field and in other laboratory experiments (personal observation). Future work should focus on interactions of different tactics during actual spawning.

\section{Aggression against females}

Nest males performed fast approaches and chases against females, but this did not differ between test situations. Nest owners expel females from their nests in nature, if the females do not actively inspect shells or if they take too long to choose a shell for spawning. This may improve the chances that other, more motivated females will enter the nest, because females may also sometimes aggressively exclude each other from nests and shells (Schütz \& Taborsky 2005).

In conclusion, our results show that in the bourgeois male tactic of the snail-shell brooding cichlid L. callipterus, within-tactic competition is higher than between-tactic competition, as predicted by evolutionary theory. Additionally, our data suggest that the level of aggression 
displayed by bourgeois males towards intruders might be triggered by perceived differences in body size. We rarely found aggressive interactions among parasitic males in the different test situations, indicating that parasitic males in this species compete through scramble rather than contest competition. Our data suggest that in this species, males pursuing alternative reproductive tactics diverge in the way they respond to challenges in their social environment and to reproductive competition among representatives of the same or different tactics.

\section{References}

Arnott, G. \& Elwood, R.W. (2010) Startle durations reveal visual assessment abilities during contests between convict cichlids. Behavioural Processes, 84, 750-756.

Arnott, G. \& Elwood, R.W. (2012) Understanding how animals fight with Loyd Morgan's canon. Animal Behaviour, 84, 1095-1102.

Aubin-Horth, N.\& Dodson, J.J. (2004) Influence of individual body size and variable tresholds on the incidence of a sneaker male reproductive tactic in Atlantic Salmon. Evolution, 58, 136-144

Austad, S.N. (1984) A classification of alternative reproductive behaviors and methods for field-testing ESS models. American Zoologist, 24, 309-319.

Barata, E., Hubbard, P., Almeida, O., Miranda, A. \& Canario, A. (2007) Male urine signals social rank in the Mozambique tilapia (Oreochromis mossambicus). BMC Biology, 5, 54.

Candolin, U. \& Wong, B. (2008) Mate choice. In: Fish Behaviour (eds. Magnhagen, C., Braithwaite, V. A., Forsgren E. \& Kapoor, B. G.), 337-376. Science Publishers Ind. Enfield. NH. USA. 
Elwood, R.W. \& Arnott, G. (2012) Understanding how animals fight with Lloyd Morgan's canon. Animal Behaviour, 84, 1095-1102.

Emlen, S.T. \& Oring, L.W. (1977) Ecology, Sexual Selection, and the Evolution of mating Systems. Science, 19, 215-223.

Goffinet, O. (2007) Sperm competition and sperm characteristics of Lamprologus callipterus, a shell- brooding cichlid fish with male alternative reproductive tactics (ARTs). (Diploma Thesis), University of Zürich, Switzerland

Gross, M.R. (1982) Sneakers, Satellites and Parentals: Polymorphic Mating Strategies in North American Sunfishes. Zeitschrift für Tierpsychologie, 60, 126.

Gross, M.R. (1991) Evolution of Alternative Reproductive Strategies: FrequencyDependent Sexual Selection in Male Bluegill Sunfish. Philosophical Transactions of the Royal Society of London. Series B: Biological Sciences, $332,59-66$.

Gross, M.R. (1996) Alternative reproductive strategies and tactics: diversity within sexes. Trends in Ecology \& Evolution, 11, 92-98.

Hammerstein, P. (1981) The role of asymmetries in animal contests. Animal Behaviour, 29, 193-205.

Hirschenhauser, K., Ros, A., Carneiro, L., Oliveira, T., Silva, A., Canario, A. \& Oliveira, R. (2002) Non-invasive hormone assessment from fish-holding water. Advances in Ethology, 37, 139.

Hirschenhauser, K., Taborsky, M., Oliveira, T., Canàrio, A.V.M. \& Oliveira, R.F. (2004) A test of the 'challenge hypothesis' in cichlid fish: simulated partner and territory intruder experiments. Animal Behaviour, 68, 741-750. 
Hothorn, T., Bretz, F. \& Westfall, P. (2008) Simultaneous Inference in General Parametric Models. Biometrical Journal, 50, 346-363.

Knell, R.J. \& Simmons, L.W. (2010) Mating tactics determine patterns of condition in a dimorphic beetle. Proceedings of the Royal Society B: Biological Sciences, 277, 2347-2353.

Laumen, J., Pern, U. \& Blüm, V. (1974) Investigations on the function and hormonal regulation of the anal appendices in Blennius pavo (risso). Journal of Experimental Zoology, 190, 47-56.

Maan, M.E. \& Taborsky, M. (2008) Sexual conflict over breeding substrate causes female expulsion and offspring loss in a cichlid fish. Behavioral Ecology, 19, 302-308.

Maynard Smith, J. (1974) The theory of games and the evolution of animal conflicts. Journal of theoretical Biology, 47, 209-221.

Mitchell, J.S., Wirtz Ocana, S. \& Taborsky, M. (2014) Male and female shell-brooding cichlids prefer different shell characteristics. Animal Behaviour 98:131-137

Neat, F.C., Locatello, L. \& Rasotto, M.B. (2003) Reproductive morphology in relation to alternative male reproductive tactics in Scartella cristata. Journal of Fish Biology, 62, 1381-1391.

Neff, B.D., Fu, P. \& Gross, M.R. (2003) Sperm investment and alternative mating tactics in bluegill sunfish (Lepomis macrochirus). Behavioral Ecology, 14, 634641.

Oliveira, R.F., Hirschenhauser, K., Carneiro, L.A. \& Canario, A.V.M. (2002) Social modulation of androgen levels in male teleost fish. Comparative Biochemistry and Physiology Part B: Biochemistry and Molecular Biology, 132, 203-215. 
Oliveira, R.F., Hirschenhauser, K., Canário, A.V.M. \& Taborsky, M. (2003) Androgen levels of reproductive competitors in a co-operatively breeding cichlid. Journal of Fish Biology, 63, 1615-1620.

Oliveira, R.F., Taborsky, M. \& Brockmann, H.J. (2008) Alternative reproductive tactics: an integrative approach Cambridge University Press (eds R.F. Oliveira, M. Taborsky and H.J. Brockmann), 1-521.

Parker, G.A. (1974) Assessment strategy and the evolution of fighting behaviour. Journal of theoretical Biology, 47, 223-243.

Parker, G.A. (1982). Phenotype-limited evolutionary stable strategies. Current Problems in Sociobiology, 173-201.

Pinheiro, J. Bates, D., DebRoy, S. \& Sakar, D. (2012) R Development Core Team. nlme: Linear and nonlinear mixed effexts models, 2012. R package version , 3.1-103.

Raveh, S., Heg, D., Vincent, V., Coltman, D., Jamieson, G., Dobson, F., Balmer, A. \& Neuhaus, P. (2010). Male reproductive tactics to increase paternity in the polygynandrous Canadian ground squirrel (Urocitellus Columbianus). Behavioural Ecology and Sociobiology, 1-2.

Ryan, M.J., Craig M.P. \&. Morris M.R. (1992) A genetic polymorphism in the swordtail Xiphophorus nigrensis: testing the prediction of equal fitnesses." American Naturalist: 21-31.

Sakia, R. (1992) The Box-Cox transformation technique: a review. The statistician, 169-178.

Sato, T. (1994) Active accumulation of spawning substrate: a determinant of extreme polygyny in a shell-brooding cichlid fish. Animal Behaviour, 48, 669-678. 
Sato, T., Hirose, M., Taborsky, M. \& Kimura, S. (2004) Size-Dependent Male Alternative Reproductive Tactics in the Shell-Brooding Cichlid Fish Lamprologus callipterus in Lake Tanganyika. Ethology, 110, 49-62.

Schaedelin, F.C. \& Taborsky, M. (2006) Mating craters of Cyathopharynx furcifer (Cichlidae) are individually specific, extended phenotypes. Animal Behaviour, 72, 753-761.

Schaedelin, F.C. \& Taborsky, M. (2009) Extended phenotypes as signals. Biological Reviews, 84, 293-313.

Schradin, C., Schneider C. \&. Lindholm A.K. (2010) The nasty neighbour in the striped mouse (Rhabdomys pumilio) steals paternity and elicits aggression. Frontiers in Zoology, 7: 19.

Schütz, D. \& Taborsky, M. (2005) The influence of sexual selection and ecological constraints on an extreme sexual size dimorphism in a cichlid. Animal Behaviour, 70, 539-549.

Schütz, D., Pachler, G., Ripmeester, E., Goffinet, O. \& Taborsky, M. (2010) Reproductive investment of giants and dwarfs: specialized tactics in a cichlid fish with alternative male morphs. Functional Ecology, 24, 131-140.

Schütz, D., Heg-Bachar, Z., Taborsky, M., \& Heg, D. (2012). Spawning coordination of mates in a shell brooding cichlid. International journal of evolutionary biology, 2012.

Scott, A.P. \& Ellis, T. (2007) Measurement of fish steroids in water-a review. General and comparative endocrinology, 153, 392-400.

Scott, A.P., Hirschenhauser, K., Bender, N., Oliveira, R., Earley, R.L., Sebire, M., Ellis, T. et al. (2008) Non-invasive measurement of steroids in fish-holding 
water: important considerations when applying the procedure to behaviour studies. Behaviour, 145, 1307-1328.

Shuster, S. \& Wade, M.J (1991) Equal mating success among male reproductive strategies in a marine isopod. Nature, 350, 608-610.

Shuster, S.M. \& Wade, M.J. (2003) Mating Systems and Strategies. Princeton University Press.

Smith, J.M. \& Parker, G.A. (1976) The logic of asymmetric contests. Animal Behaviour, 24, 159-175.

Taborsky, M. (1984) Broodcare helpers in the cichlid fish Lamprologus brichardi: Their costs and benefits. Animal Behaviour, 32, 1236-1252.

Taborsky, M. (1994) Sneakers, satellites, and helpers: parasitic and cooperative behavior in fish reproduction. Adv Study Behav, 23, 1-100.

Taborsky, M. (1997) Bourgeois and parasitic tactics: Do we need collective, functional terms for alternative reproductive behaviours? Behavioural Ecology and Sociobiology. 41: 361-362.

Taborsky, M. (1998) Sperm competition in fish: "bourgeois" males and parasitic spawning. Trends in Ecology \& Evolution, 13, 222-227.

Taborsky, M. (2001) The Evolution of Bourgeois, Parasitic, and Cooperative Reproductive Behaviors in Fishes. Journal of Heredity, 92, 100-110.

Taborsky, M., Oliveira, R. \& Brockmann, H.J. (2008) The evolution of alternative reproductive tactics: concepts and questions. In: Alternative Reproductive (eds R.F. Oliveira, M. Taborsky and H.J. Brockmann), Cambridge University Press 1-22. 
Taborsky, M. (2008) Alternative reproductive tactics in fish. In: Alternative Reproductive Tactics. Cambridge University Press (eds R.F. Oliveira, M. Taborsky and H.J. Brockmann), 251-299.

Taborsky, M. \& Brockmann, H.J. (2010) Alternative Reproductive tactics and life history phenotypes. In: Animal Behaviour: Evolution and Mechanisms (Ed. P. Kappeler). Springer, Berlin, 537-586.

Thornhill, R. (1984) Fighting and Assessment in Harpobittacus Scorpionflies. Evolution, 38, 204-214.

Toquenaga, Y. (1990) The Mechanisms of Contest and Scramble Competition in Bruchid Species. Bruchids and Legumes: Economics, Ecology and Coevolution (eds K. Fujii, A.M.R. Gatehouse, C.D. Johnson, R. Mitchel \& T. Yoshida), Springer Netherlands, 341-349.

Trewavas, E. (1983) Tilapiine fishes of the genera Sarotherodon, Oreochromis and Danakilia. Natural History Museum Publications.

Tschernavin, V. (1938) Changes in the salmon skull. Transactions of the Zoological Socienty of London, 24, 104-184.

Uglem, I., Mayer, I. \& Rosenqvist, G. (2002) Variation in Plasma Steroids and Reproductive Traits in Dimorphic Males of Corkwing Wrasse (Symphodus melops L.). Hormones and Behavior, 41, 396-404.

Venables, W.N. \& Ripley, B.D. (2002) Modern Applied Statistics with S. Fourth Edition. Springer, New York.

von Kuerthy, C., Tschirren, L. \& Taborsky, M. ( 2015) Alternative reproductive tactics in snail-shellbrooding cichlids diverge in energy reserve allocation. Ecology and Evolution in press 5(10): 2060-2069. 
Warner, R.R. (1984) Mating behavior and hermaphroditism in coral reef fishes. American Scientist, 72, 128-136.

Wirtz Ocaña, S., Schütz, D., Pachler, G. \& Taborsky, M. (2013) Paternal inheritance of growth in fish pursuing alternative reproductive tactics. Ecology and Evolution, 1614-1625.

Wirtz Ocaña S., Meidl, P., Bonfils, D. \& Taborsky, M. (2014) Y-linked Mendelian inheritance of giant and dwarf male morphs in shell-brooding cichlids. Proceedings of the Royal Society B: Biological Sciences, 281.

Zimmerer E.J. \& Kallman K.D (1989) Genetic basis of alternative reproductivetactics in the Pygmy Swordtail, Xiphophorus nigrensis. Evolution, 43, 1298-1307. 


\section{Figure legends}

Fig.1: Experimental design: 1. Pre-exposure phase: The nest male spends the first hour with two females in a 500 litre compartment. 2. Non-competitive or competitive exposure phase: A nest male is challenged by one of five possible test situations during the second hour of the experiment (a-e). a) Control, without intruder male. b) Nest male intruder, c) two sneaker males, d) two dwarf males and e) one sneaker and one dwarf male. Behavioural observations 20 min and 40 min after the start of the exposure phase are marked with an X.

Fig. 2. Amount of time (seconds) nest males spent in aggressive behaviour (including overt and restrained aggression) when exposed to competitors in the different test situations. The plot shows medians and Interquartile ranges (IQR), significant differences are marked with asterisks.

Fig. 4. Amount of time (seconds) nest males spent with (a) courtship and (b) nest maintenance behaviours when exposed to competitors in the different test situation. The plots show medians and interquartile ranges (IQR), significant differences are marked with asterisks.

Fig. 5. Relationship between (a) aggressive behaviours towards intruder males and courtship behaviours towards females and (b) aggressive behaviours towards intruder males and nest maintenance behaviour when exposed to competitors in different treatment groups. In the control group with no intruder males, aggression levels (towards other males) are zero. The 
plots show the medians and interquartile ranges (IQR) of both behavioural categories along both axes.

Fig. A1. (a) Restrained and (b) overt aggression (displays) of nest males when exposed to competitors in the different test situations. Plots show medians and interquartile ranges (IQR). For an overview of the statistical results see Tables 6-11 in the supplementary material. 


\section{Tables and legends}

Table 1 Aggressive behaviour displayed by nest males when challenged by different competitive test situations (Fig. 1 b-e).

\begin{tabular}{lllll}
\hline Comp. of test situations & Estimated & $S E$ & $Z$ & $P$ \\
Linear Hypothesis & difference & & & \\
\hline $\mathrm{Nm}-\mathrm{Sn}=0$ & -3.1384 & 1.0684 & -2.938 & $\mathbf{0 . 0 1 7}$ \\
$\mathrm{Nm}-\mathrm{SnDw}=0$ & -3.8317 & 1.0476 & -3.657 & $\mathbf{0 . 0 0 1}$ \\
$\mathrm{Nm}-\mathrm{Dw}=0$ & -8.5773 & 1.0684 & -8.028 & $<\mathbf{0 . 0 0 1}$ \\
$\mathrm{Sn}-\mathrm{SnDw}=0$ & -0.6933 & 1.0476 & -0.662 & 0.911 \\
$\mathrm{Sn}-\mathrm{Dw}=0$ & -5.4389 & 1.0684 & -5.091 & $<\mathbf{0 . 0 0 1}$ \\
$\mathrm{Dw}-\mathrm{SnDw}=0$ & -4.7455 & 1.0476 & -4.530 & $<\mathbf{0 . 0 0 1}$
\end{tabular}

Multiple post-hoc tests of the time (seconds) focal nest males spent with aggressive behaviour when exposed to competitors in the different test situations $(\mathrm{Nm}=$ Nest male intruder, $\mathrm{Sn}=$ Sneaker intruders, $\mathrm{Dw}=$ Dwarf male intruders, $\mathrm{SnDw}=\mathrm{Mix}$ of one sneaker and one dwarf male). Tests were performed against the null hypothesis that the difference between each compared pair equals zero. $P$ values were adjusted for multiple comparisons. $\mathrm{SE}=$ standard error. Significant $p$-values are marked in bold. 
Table 2 Comparison of courting behaviour (seconds) performed by nest males when exposed to the different test situations (Fig. 1 a-e).

\begin{tabular}{lc}
\hline Comp. of test situations & $P$ \\
\hline Nm - control & $\mathbf{0 . 0 3 4}$ \\
Sn - control & $\mathbf{0 . 0 0 3}$ \\
SnDw - control & $\mathbf{0 . 0 2 5}$ \\
Dw - control & $\mathbf{0 . 0 4 4}$ \\
Nm - Sn & 0.966 \\
Nm - SnDw & 1 \\
Nm - Dw & 0.999 \\
Sn - Dw & 0.923 \\
Sn - SnDw & 0.971 \\
Dw - SnDw & 0.999
\end{tabular}

Results from permutation tests (10,000). Significant $P$ values are marked in bold. 
Table 3 Nest maintenance behaviour displayed by nest males when challenged by different competitive test situations (Fig. 1 a-e).

\begin{tabular}{llllr}
\hline Comp. of test situations & Estimated & $S E$ & $Z$ & $P$ \\
Linear Hypothesis & difference & & & \\
\hline $\mathrm{Nm}-$ control $=0$ & -2.14227 & 0.78292 & -2.736 & $\mathbf{0 . 0 4 9}$ \\
$\mathrm{Sn}-$ control $=0$ & -1.34731 & 0.7671 & -1.756 & 0.399 \\
$\mathrm{SnDw}-$ control $=0$ & -0.72110 & 0.76710 & -0.940 & 0.881 \\
$\mathrm{Dw}-$ control $=0$ & 0.04727 & 0.76710 & 0.062 & 1.000 \\
$\mathrm{Nm}-\mathrm{Sn}=0$ & 0.794696 & 0.78292 & 1.015 & 0.848 \\
$\mathrm{Nm}-\mathrm{Dw}=0$ & 2.18955 & 0.78292 & 2.797 & $\mathbf{0 . 0 4 1}$ \\
$\mathrm{Nm}-\mathrm{SnDw}=0$ & 1.42117 & 0.78292 & 1.815 & 0.365 \\
$\mathrm{Sn}-\mathrm{Dw}=0$ & 1.39459 & 0.76710 & 1.1818 & 0.363 \\
$\mathrm{Sn}-\mathrm{SnDw}=0$ & 0.62621 & 0.76710 & 0.816 & 0.925 \\
$\mathrm{Dw}-\mathrm{SnDw}=0$ & 0.76837 & 0.76710 & 1.002 & 0.854 \\
\end{tabular}

Multiple post-hoc tests of the time (seconds) focal nest males spent with nest maintenance behaviour when exposed to competitors in the different test situations, or in the control. Tests were performed against the null hypothesis that the difference between each compared pair equals zero. $P$ values were adjusted for multiple comparisons. $S E=$ standard error. Significant $P$ values are marked in bold. 
1. Pre - Exposure - Phase: 2. Exposure - Phase:

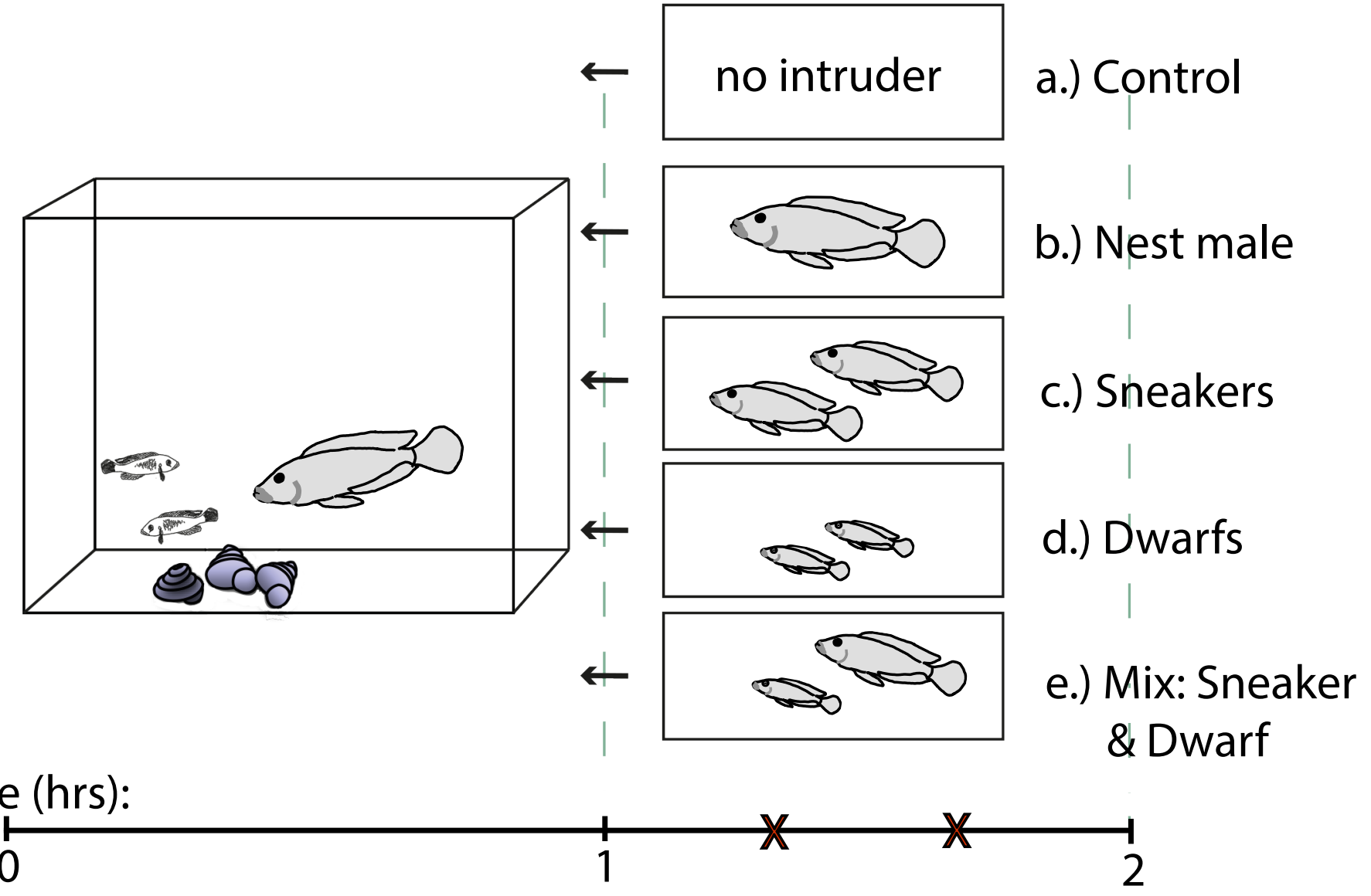

Time 


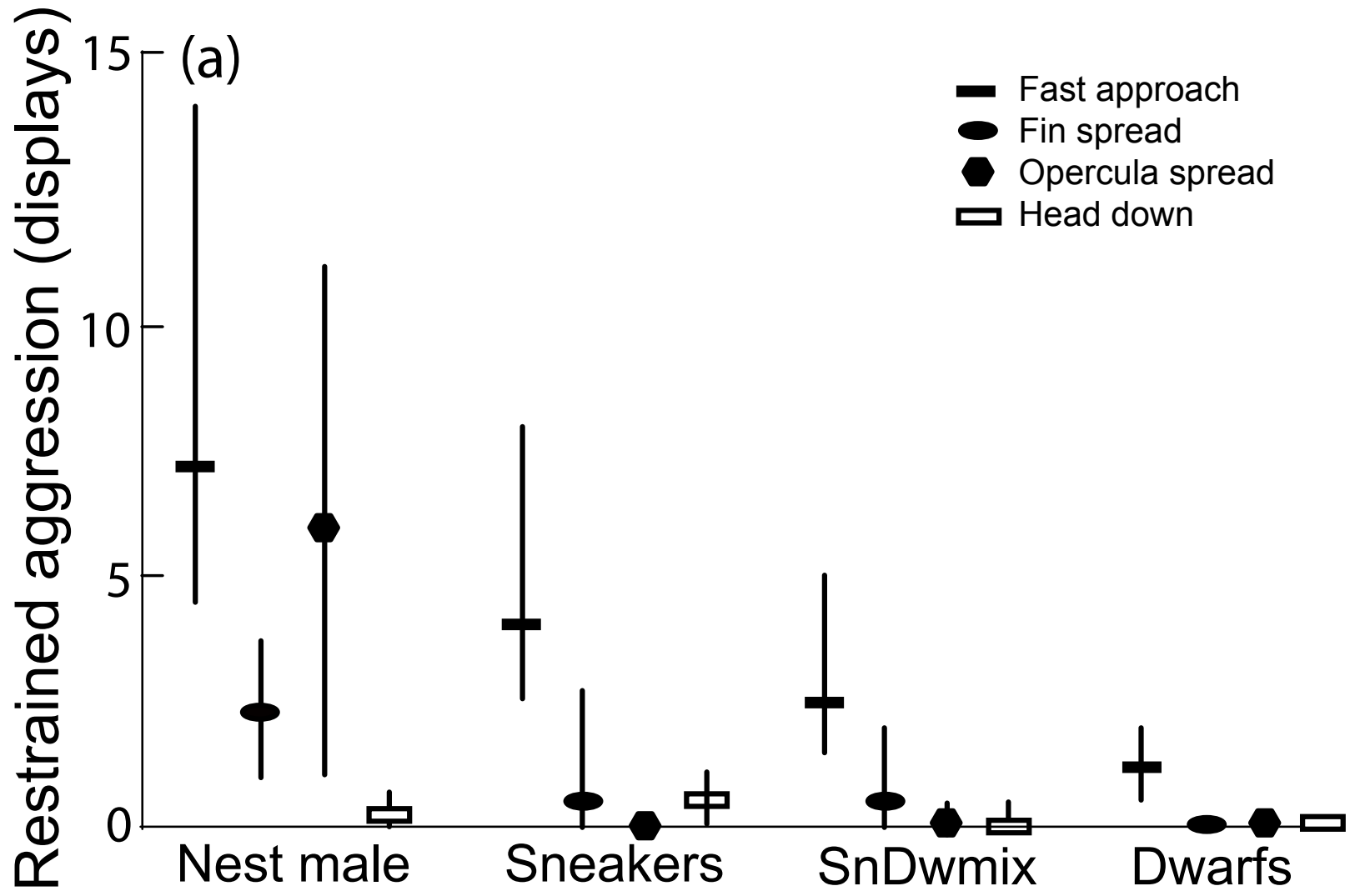




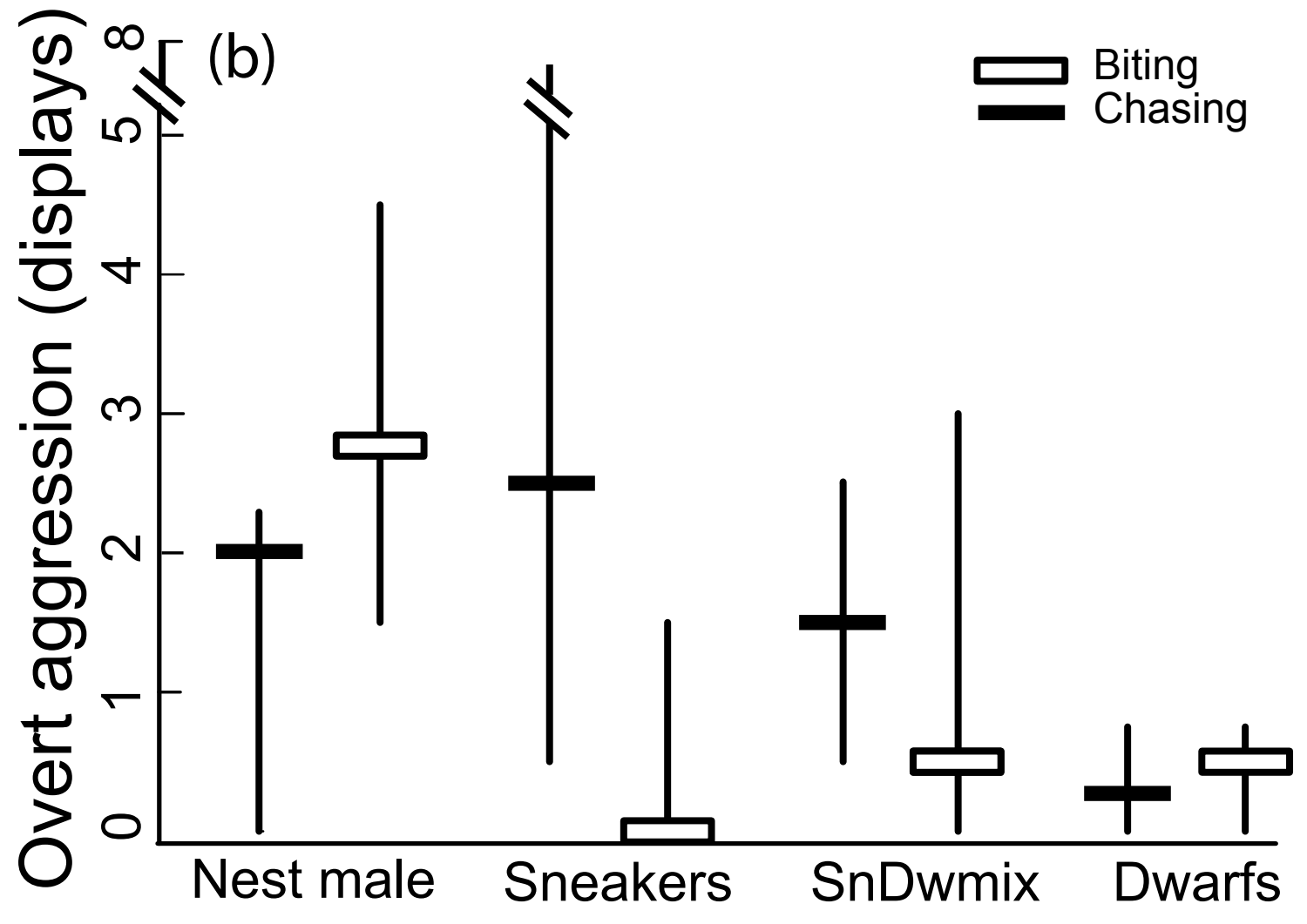




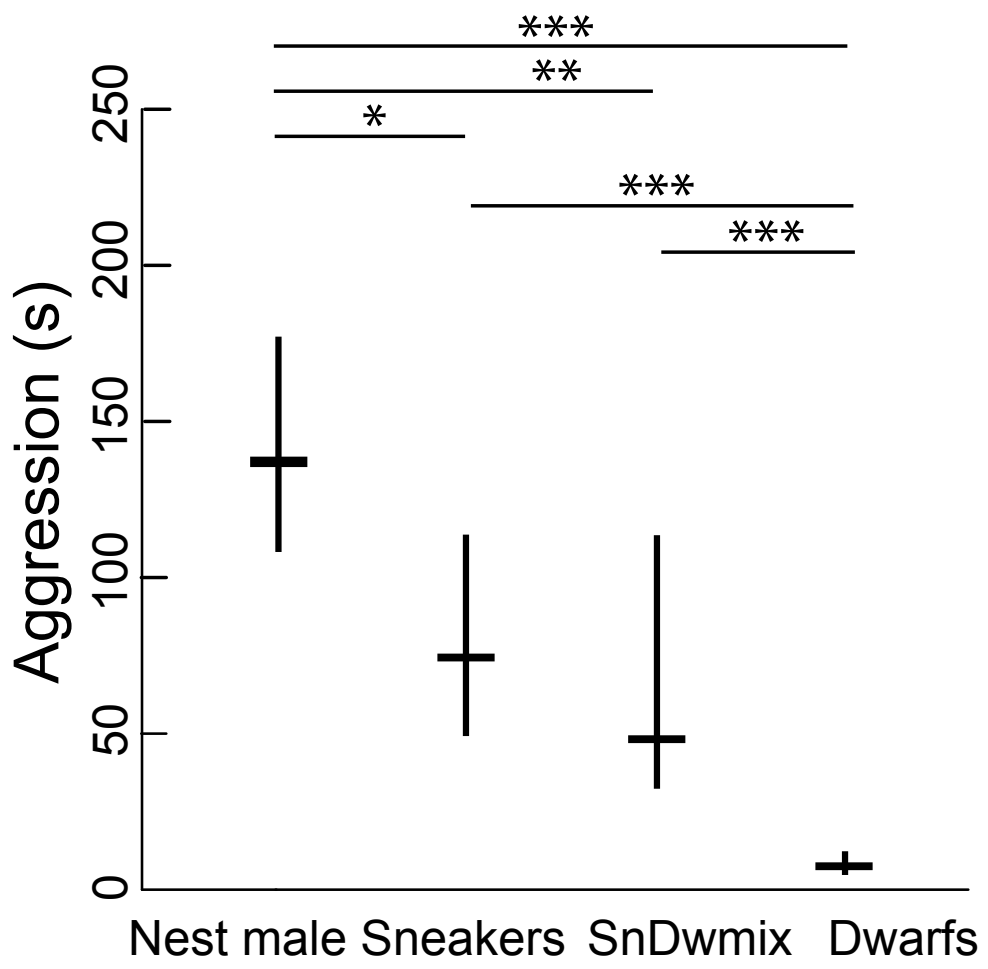




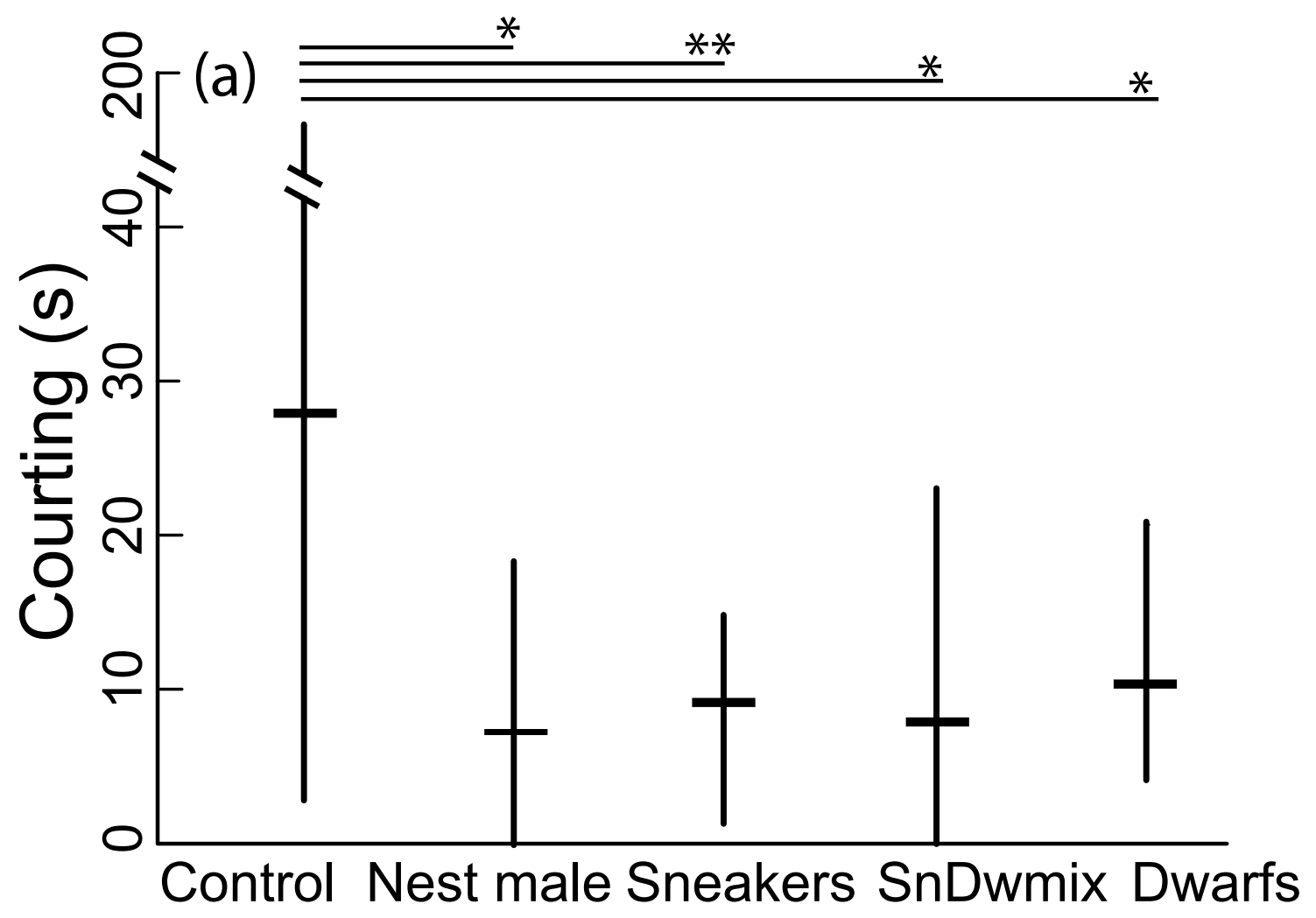




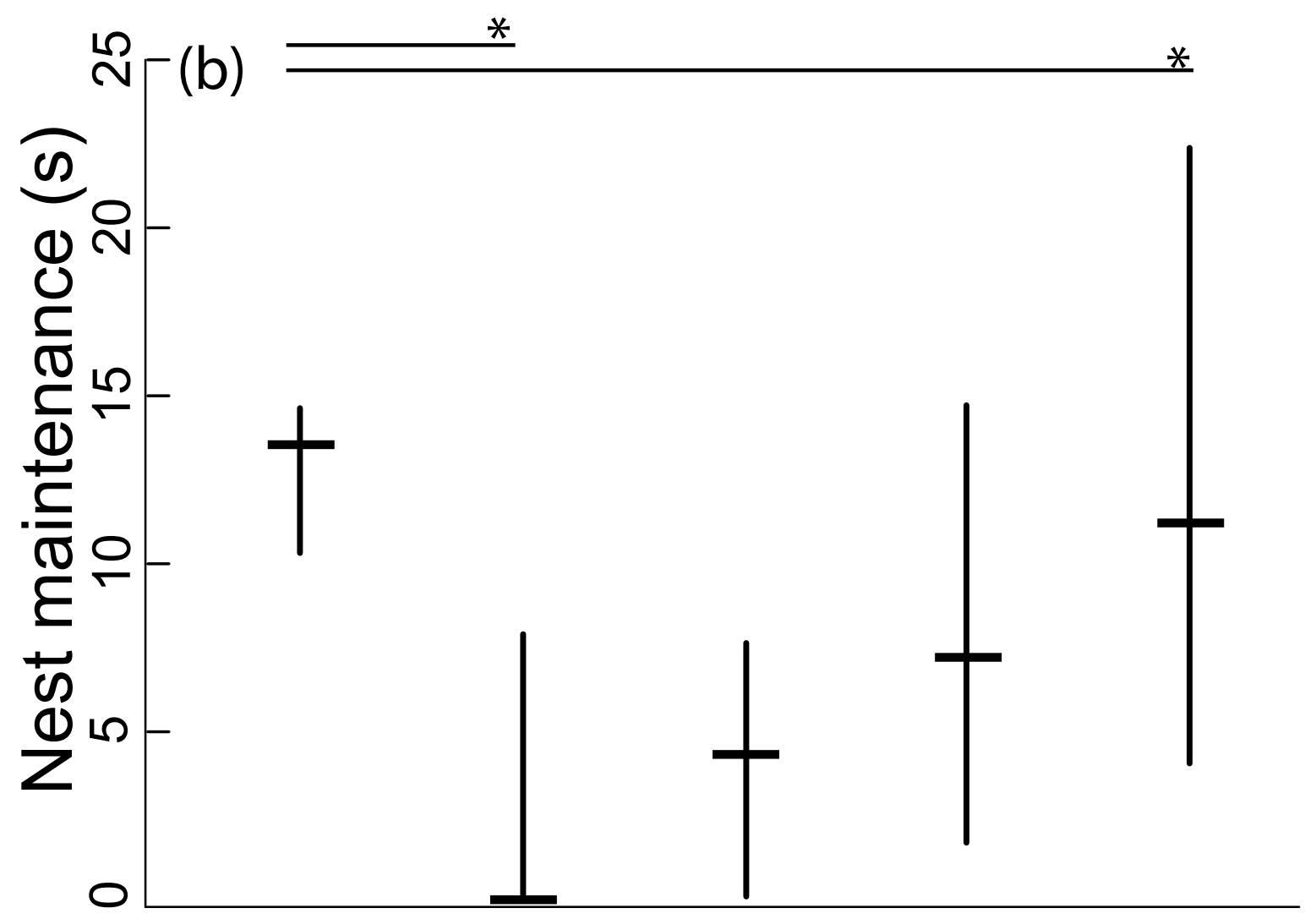

Control Nest male Sneakers SnDwmix Dwarfs 


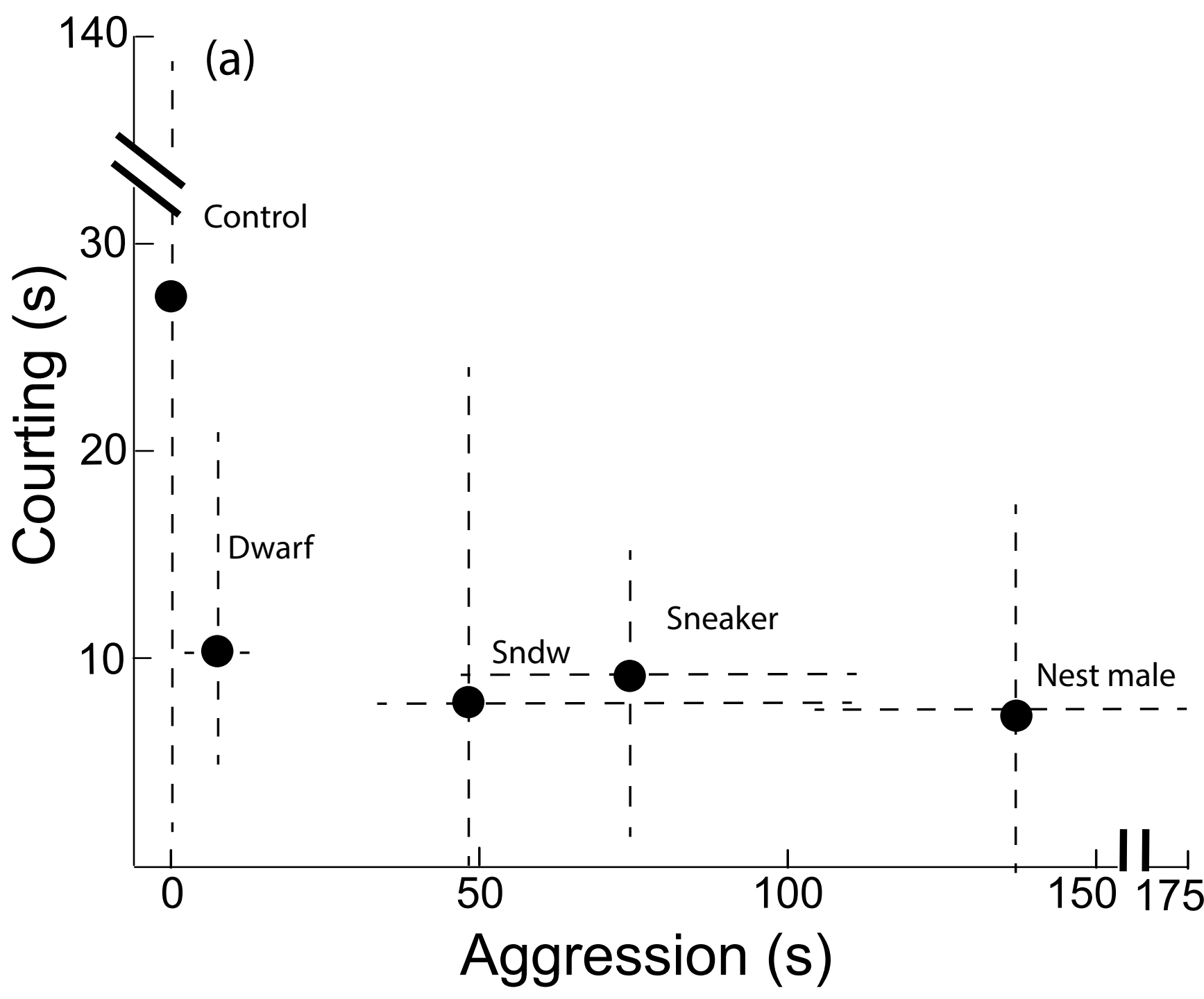




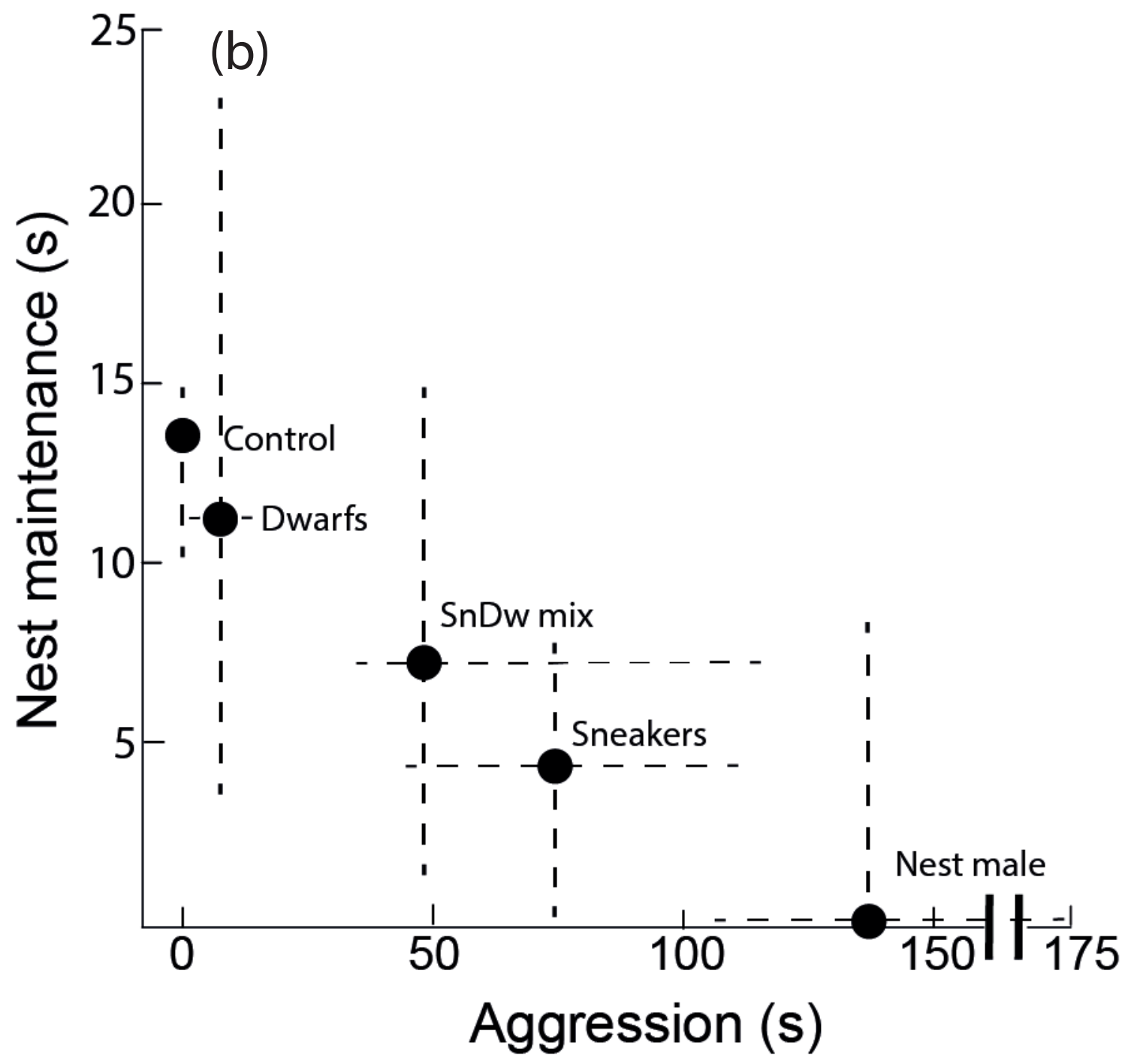

